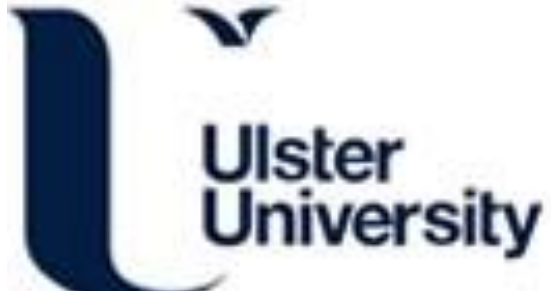

\section{Practical Application of the Learning Mechanics-Game Mechanics (LM-GM) framework for Serious Games Analysis in Engineering Education}

Callaghan, MJ., McShane, N., Gomez-equiluz, A., Teillès, T., \& Raspail, P. (2016). Practical Application of the Learning Mechanics-Game Mechanics (LM-GM) framework for Serious Games Analysis in Engineering Education. In Unknown Host Publication (pp. 391-395). IEEE. https://doi.org/10.1109/REV.2016.7444510

Link to publication record in Ulster University Research Portal

\section{Published in:}

Unknown Host Publication

Publication Status:

Published online: 31/03/2016

DOI:

10.1109/REV.2016.7444510

\section{Document Version}

Author Accepted version

\section{General rights}

Copyright for the publications made accessible via Ulster University's Research Portal is retained by the author(s) and / or other copyright owners and it is a condition of accessing these publications that users recognise and abide by the legal requirements associated with these rights.

\section{Take down policy}

The Research Portal is Ulster University's institutional repository that provides access to Ulster's research outputs. Every effort has been made to ensure that content in the Research Portal does not infringe any person's rights, or applicable UK laws. If you discover content in the Research Portal that you believe breaches copyright or violates any law, please contact pure-support@ulster.ac.uk. 


\title{
Practical Application of the Learning Mechanics- Game Mechanics (LM-GM) framework for Serious Games Analysis in Engineering Education
}

\author{
MJ.Callaghan, N.McShane, A. Gómez Eguíluz, T. Teillès and P. Raspail \\ School of Computing and Intelligent Systems \\ University of Ulster, Derry, Northern Ireland, UK \\ mj.callaghan@ulster.ac.uk
}

\begin{abstract}
Serious Games (SG) have proved to have instructional potential but there is still a lack of methodologies and tools not only for their design but also to support game analysis and assessment. This paper explores the use of SG to increase student engagement and retention. The ongoing development phase of a game to teach the theoretical and practical principles of the operation of a sound synthesizer is presented to demonstrate how electronic engineering education can be radically reimagined to create immersive, highly engaging learning experiences that are problem-centered and pedagogically sound. The Learning Mechanics-Game Mechanics (LM-GM) framework for SG game analysis is introduced and its use in an educational game design scenario is shown as a case study.

Index Terms-Engineering Education; Learning MechanicsGame Mechanics (LM-GM) model; Game based learning.
\end{abstract}

\section{INTRODUCTION}

Serious Games have proved to have instructional potential due to their ability to present realistic simulations of real-life situations [1-4]. However educational games need to be designed properly to find the correct balance between gameplay and learning objectives and the integration of educational and game design principles [56]. One possible approach to this problem is the use of the Learning Mechanics-Game Mechanics (LM-GM) framework which supports SG analysis and design by allowing reflection on the various pedagogical and game elements involved [7]. This paper provides a practical example and case study of using the (LM-GM) framework for game design for teaching electronic engineering and shows how a commercial game engine (Unity3D) can be used to rapidly prototype simulations to teach electronic/electrical circuit theory where students must use and apply their knowledge and understanding of circuit theory to bias electronics circuit successfully to complete the game. The game is designed to complement existing teaching resources while ensuring a high level of user engagement/replay ability with a competitive leaderboard element and analytics to measure student retention.

Section II of this paper discusses the practical use of game based learning in electronic and electrical engineering. Section III introduces the Sand Box Serious Game approach and Learning Mechanics-Game Mechanics (LM-GM) framework and demonstrates their use in the design of a sound synthesizer game for teaching electronic and electrical engineering. Sections IV and V presents a practical example of a mobile game designed using these approaches and looks at the practicalities of assessment and integration of analytics in this context. Section VI presents the conclusion and future work in this area.

\section{GAME BASED LEARNING IN ENGINEERING}

When attempting to use a game based learning approach to teach a topic for the first time, the main initial challenge to overcome would be how to repurpose and re-imagine existing teaching material as a game where the resulting student experience is designed in an appropriate and compelling way [8-9]. As an example of this process consider teaching a student about the theoretical underpinnings of oscillator operation and its use in a physical circuit. Oscillators are astable devices that produce an alternating or pulsing output voltage which is primarily dependent on the individual values of resistor/capacitor combinations chosen. A practical use of an oscillator would be in the design of a sound synthesizer, an electronic musical instrument which generates electric signals that are converted to sounds through headphones or loudspeakers. Synthesizers typically use oscillator circuits to generate frequencies/tones that can be subsequently shaped by filters and amplifiers e.g. an audio astable multivibrator built around the integrated-circuit 555 timer chip (Figure 1). An astable multivibrator has two output states, neither of which is stable which the circuit oscillates between. Selecting different values of individual components in the circuit (e.g. R1 and $\mathrm{C} 1$ ) allows the frequency or pitch of the oscillator to be varied based on the formula shown.

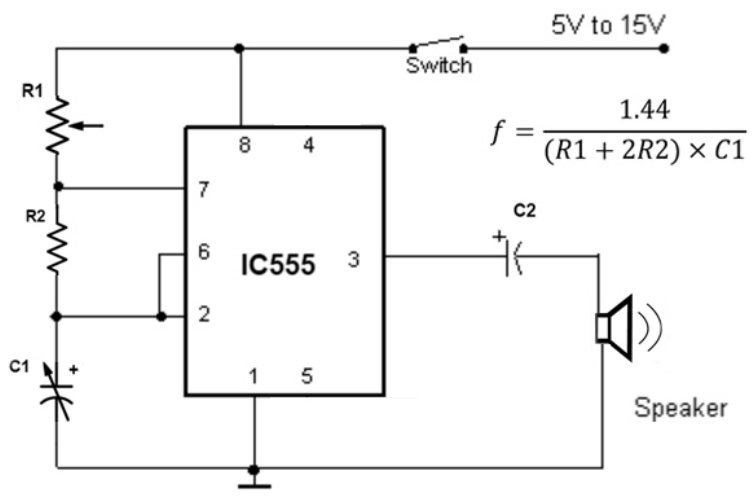

Figure 1 Audio astable multivibrator/tone generator

Creating a game to teach some aspects of these concepts (the scope was limited for the purpose of this example) would involve translating the student objectives, underpinning theoretical material and learning outcomes (Table 1) into a new format/medium in an effective manner while not taking away from or diluting the main objective of the exercise i.e. student understanding and learning. 
Table 1. Objectives, related theory and learning outcomes

\begin{tabular}{|c|c|c|}
\hline Objectives & Theory & Learning outcomes \\
\hline $\begin{array}{c}\text { Solve for } \mathrm{R} 1 \mathrm{\&} \\
\mathrm{C} 1 \text { given } \mathrm{V}, \mathrm{R} 2 \\
\text { and } \mathrm{C} 2 \text { to get } \\
\text { required value } \\
\text { of Frequency } \mathrm{f}\end{array}$ & $f=\frac{1.44}{(R 1+2 R 2) \times C 1}$ & $\begin{array}{c}\text { Understand role of } \\
\text { multivibrator circuits in } \\
\text { oscillator design. Practical } \\
\text { operation of a tone } \\
\text { generator circuit. }\end{array}$ \\
\hline
\end{tabular}

Games are typically built around a core loop i.e. something the player(s) does over and over again, which in this instance would be to ask the student to calculate and then select the correct values and permutations of resistor $\mathrm{R} 1$ and capacitor $\mathrm{C} 1$ from the bank of available component values, when the values of the supply voltage, resistor $\mathrm{R} 2$ and capacitor $\mathrm{C} 2$ are fixed and known, to generate the given value of Frequency $f$, where the value of Frequency is different each time the game is played (Figure 2).

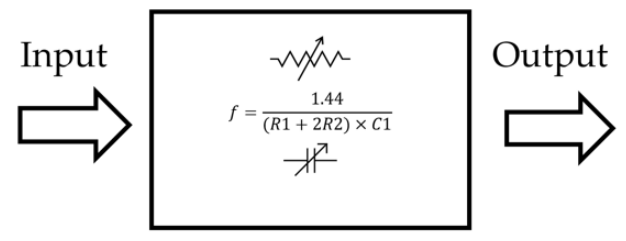

Stimulus

Response

Figure 2 Core game loop audio astable multivibrator game

To determine the validity/viability of this approach as a game a prototype was created and modelled in Excel to fine-tune core gameplay, identify typical component values and resultant output frequencies (Figure 3).

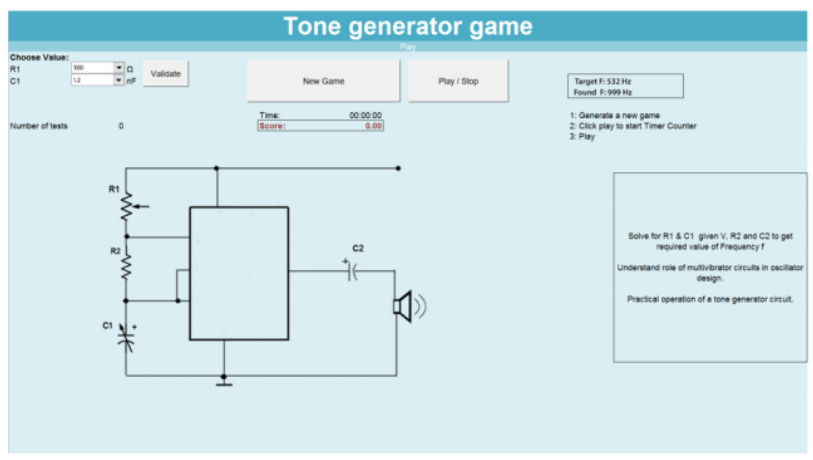

Figure 3 Solve for R1 and C1 to achieve target output frequency

The score achieved is based on how close the value of actual output of the circuit (frequency) was to the target output of the circuit and expressed as a percentage. To do this successfully would require the student to have a clear understanding of both the underlying circuit theory and its application. The scoring mechanism provides feedback to the student on their level of understanding of circuit theory as there is a direct correlation between the percentage value received and accuracy of the result. A timer was included to add a competitive element to the game.

\section{SAND BOX SERIOUS GAMES/LM-GM APPROACH}

The game created in Microsoft Excel was functional, theoretically and pedagogically sound and could be used as a supplementary teaching resource but it would not be described as an engaging student experience with a high level of replay value and did not a include a real physical element i.e. how could this circuit be used in a practical real world example. To explore this idea further the game scope was extended with a view to addressing these shortcomings and to find a way to integrate the game elements and learning objectives in a more compelling way. A game backstory, physical environment, setting, initial challenge, puzzles and feedback was created using the heuristic framework for educational games where the game is considered as a narrative [10] and provides a structured and systematic approach to the integration of the story with the learning outcomes (Table 3).

Table 3. Heuristic approach educational games (Dickey 2006)

\begin{tabular}{|c|c|}
\hline Heuristic approach & Tone generator game \\
\hline $\begin{array}{c}\text { Present initial challenge } \\
\text { Idify potential obstacles and } \\
\text { challenges and resources }\end{array}$ & $\begin{array}{c}\text { Call to action/repair circuit. } \\
\text { Apply practical electronic } \\
\text { circuit theory to complete } \\
\text { puzzles }\end{array}$ \\
\hline Identify and establish roles & Play role of engineer \\
\hline $\begin{array}{c}\text { Establish the physical, temporal } \\
\text { and environmental dimensions } \\
\text { of environment }\end{array}$ & $\begin{array}{c}\text { Game setting is industrial. } \\
\text { Add time constraints to } \\
\text { complete tasks }\end{array}$ \\
\hline $\begin{array}{c}\text { Create the backstory } \\
\text { Add cut scenes to } \\
\text { support narrative }\end{array}$ & $\begin{array}{c}\text { Use of cut scenes for plot } \\
\text { hooks and to progress story }\end{array}$ \\
\hline
\end{tabular}

A Sand Box Serious Game (SBSG) approach was used as the task based nature of the game design lends itself to an experiential and exploratory learning format [11]. The Learning Mechanics - Game Mechanics (LM-GM) framework for supporting serious games analysis was employed to map the pedagogical elements and learning outcomes of the game to game mechanics (Figure/table 4).
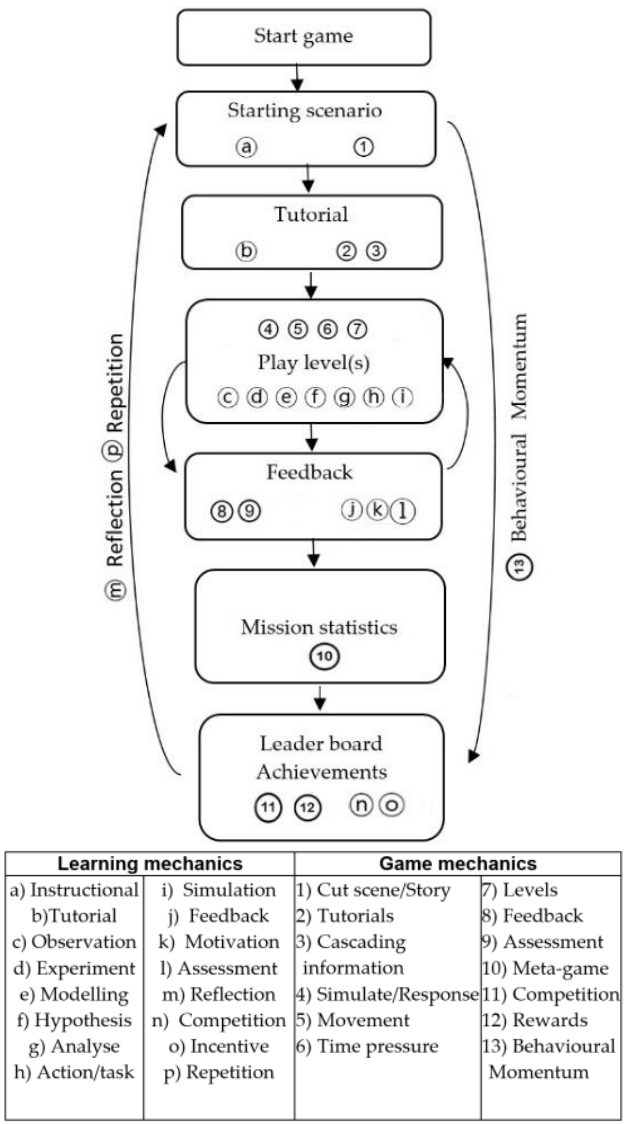

Figure 4. Tone game mapping using LM-GM-based analysis 
Table 4. Tone Generator extended LM-GM-based analysis

\begin{tabular}{|c|c|c|c|}
\hline Game mechanic & Implementation & Learning mechanic & Description \\
\hline Cut scene/Story & $\begin{array}{c}\text { Pre-rendered videos explain the game } \\
\text { objectives, mechanics and outcomes } \\
\text { through storytelling }\end{array}$ & Instructional & $\begin{array}{l}\text { Backstory sets game scenario. Player must fix } \\
\text { the circuit to escape the room }\end{array}$ \\
\hline $\begin{array}{c}\text { Tutorials } \\
\text { Cascading information }\end{array}$ & $\begin{array}{l}\text { Tutorials at start of game guide user } \\
\text { through basic mechanics of moving } \\
\text { and biasing the circuits }\end{array}$ & Guidance/Tutorial & $\begin{array}{l}\text { Player is guided through the initial stages of } \\
\text { the game by informative graphics and cut } \\
\text { scenes. }\end{array}$ \\
\hline Simulate/Response & $\begin{array}{l}\text { Player must select correct value of } \\
\text { component(s) in circuit to achieve } \\
\text { required output values/response. }\end{array}$ & $\begin{array}{l}\text { Observation, Analyse } \\
\text { Experimentation } \\
\text { Modelling, Hypothesis }\end{array}$ & $\begin{array}{l}\begin{array}{c}\text { Game play tasks such as correctly biasing } \\
\text { circuits provide the player with a sense of } \\
\text { empowerment. }\end{array} \\
\end{array}$ \\
\hline Movement & $\begin{array}{c}\text { Navigate player token around 3D } \\
\text { environment }\end{array}$ & \multirow[t]{2}{*}{ Action/Task } & \multirow{2}{*}{$\begin{array}{c}\text { Performing interactive tasks successfully and } \\
\text { completing levels provides a sense of progress, } \\
\text { player satisfaction and game mastery. }\end{array}$} \\
\hline Time pressure & $\begin{array}{c}\text { Complete each level within time } \\
\text { constraint }\end{array}$ & & \\
\hline $\begin{array}{l}\text { Levels } \\
\text { Feedback } \\
\text { Assessment } \\
\text { Meta-game }\end{array}$ & $\begin{array}{l}\text { Advance to next level. Score shows } \\
\text { time taken, accuracy and level of } \\
\text { understanding of task completed }\end{array}$ & $\begin{array}{c}\text { Feedback } \\
\text { Motivation } \\
\text { Assessment } \\
\text { Reflect }\end{array}$ & $\begin{array}{l}\text { End of level score reinforces sense of } \\
\text { understanding and progress to maintain } \\
\text { motivation. Provides benchmark for start of } \\
\text { reflection process }\end{array}$ \\
\hline $\begin{array}{l}\text { Competition } \\
\text { Rewards }\end{array}$ & Game leader board and achievements & $\begin{array}{l}\text { Competition } \\
\text { Motivation } \\
\text { Incentive } \\
\end{array}$ & $\begin{array}{c}\text { Public leader board/achievement allows } \\
\text { student to compare their score/performance to } \\
\text { other players and try to improve. }\end{array}$ \\
\hline Behavioral Momentum & $\begin{array}{l}\text { Game play repeats itself through } \\
\text { multiple levels to cause a shift in } \\
\text { behaviour on the part of the player. }\end{array}$ & Repetition & $\begin{array}{c}\text { Repetitive gameplay reinforces behaviour } \\
\text { change. Player trials multiple strategies on the } \\
\text { levels to increase overall performance. }\end{array}$ \\
\hline
\end{tabular}

The process of mapping the objectives and learning outcomes to game mechanics firstly entailed setting the game context through an instructional backstory which defined the player objectives and rationale for subsequent actions. This was achieved using cut scenes. Then the player/student was introduced to the core mechanics through a short tutorial becoming familiar with the user interface and main controls (cascading information). The core loop of the game was to solve a series of circuit problems in stages, where the player explores each puzzle (behavioural momentum), tries to understand its structure and how to efficiently solve the problem using a simulate/response approach to observe, experiment and analyse circuit behaviour under time constraints. The end of each level provides feedback to the player on their progress (score achieved), possible rewards (achievements) and competition (leader boards) as well as emerging strategies (Meta-game). To ensure the game has replay value the required output(s) of the circuit change at each stage. This approach ensures that students have to learn, fully understand and practically apply circuit theory to successfully complete each stage.

The next challenge related to the specifics of the game design i.e. how to create a compelling game with a high level of replay value which demonstrated the practical use of an oscillator in the design of a sound synthesizer. The idea for a music based game (Figure 5) was chosen where the player would have to correctly bias the circuit (i.e. select the correct permutation(s) of Resistor 1 and Capacitor 1 from a bank of available values where Resistor 2 and Capacitor 2 are fixed and provided) to generate a series of tones (output frequencies) that (roughly) equated to musical notes across an octave (Table 5) and when put together sequentially would create a simple tune/song (e.g. Twinkle twinkle little star).

\begin{tabular}{|c|c|c|c|c|c|c|}
\hline C5 & C5 & G5 & G5 & A5 & A5 & G5 \\
\hline \multicolumn{7}{|c|}{ Twin-kle } \\
\hline F5 & F5 & E5 & E5 & D5 & D5 & C5 \\
\hline \multicolumn{6}{|c|}{ How I } & won - der what you are \\
\hline
\end{tabular}

Figure 5. Frequency/notes for Twinkle Twinkle little star

This approach demonstrates the practical use of the circuit in a real world example and requires the student to develop a real understanding of the underlying circuit theory and its application and the effect of the individual circuit components on the circuit output.

Table 5. Game based on note frequencies across an octave

\begin{tabular}{|c|c|c|c|c|}
\hline Tone & C5 & D5 & E5 & F5 \\
\hline Frequency & 523.3 & 587.3 & 659.3 & 698.5 \\
\hline Tone & G5 & A5 & B5 & C6 \\
\hline Frequency & 784.0 & 880.0 & 987.8 & 1047 \\
\hline
\end{tabular}

\begin{tabular}{|l|c|c|c|c|c|c|}
\hline Tone & Req. freq. & C1 (uF) & R1 (Ohm) & R2 (Ohm) & Actual freq. & Error \% \\
\hline \multicolumn{7}{|l|}{$\mid$} \\
\hline C5 & 523.23 & 1200 & 1600 & 330 & 532.08 & 1.687 \\
\hline D5 & 587.33 & 1000 & 1800 & 330 & 586.58 & 0.127 \\
\hline E5 & 659.25 & 820 & 2000 & 330 & 661.56 & 0.351 \\
\hline F5 & 698.46 & 1200 & 1100 & 330 & 683.23 & 2.179 \\
\hline G5 & 783.99 & 820 & 1600 & 330 & 778.65 & 0.681 \\
\hline A5 & 880.00 & 1000 & 1000 & 330 & 869.27 & 1.219 \\
\hline B5 & 987.77 & 820 & 1100 & 330 & 999.86 & 1.224 \\
\hline C6 & 1046.5 & 820 & 1000 & 330 & 1060.09 & 1.299 \\
\hline
\end{tabular}

Adding a time based dynamic to the game (the quicker the student solves the puzzle the higher the score achieved) creates a competitive element and also allowed different game strategies to emerge i.e. the player can solve the puzzle(s) by accurately calculating circuit values using the formula provided which would take more time or use a heuristic/rule of thumb approach to make educated but accurate guesses and save time. 


\section{IMPLEMENTATION}

Given the near ubiquity of smart phones and tablets the final game will be designed and optimized for deployment on mobile devices using a first person perspective. A first person shooter approach was chosen as the overall experience is intended to be a competitive, fast paced action game. The physical layout of the circuit(s) are accurately recreated inside the Unity engine reflecting the constraints and dimensions of their real world counterpart (Figure 6). When the game is launched the player the splash screen sets the high level game objectives with links to a tutorial and instructions (Figure 7).
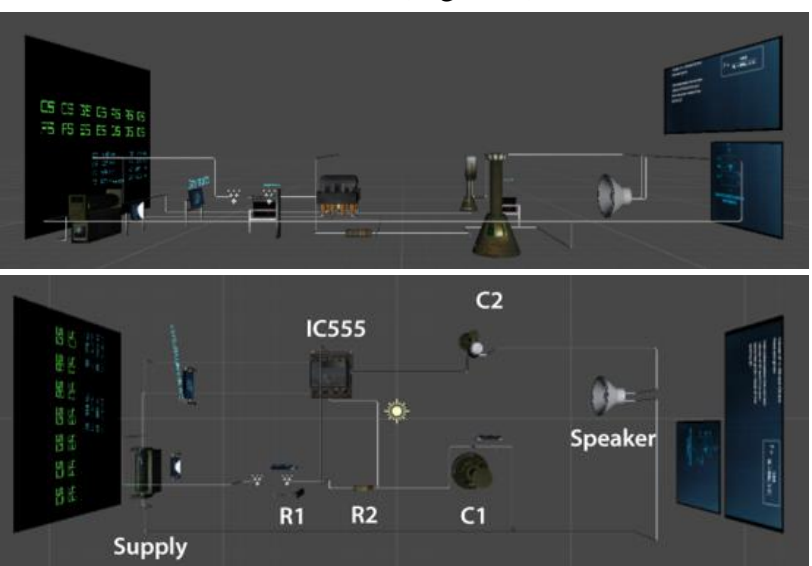

Figure 6 Level side and top view of Tone Generator circuit layout

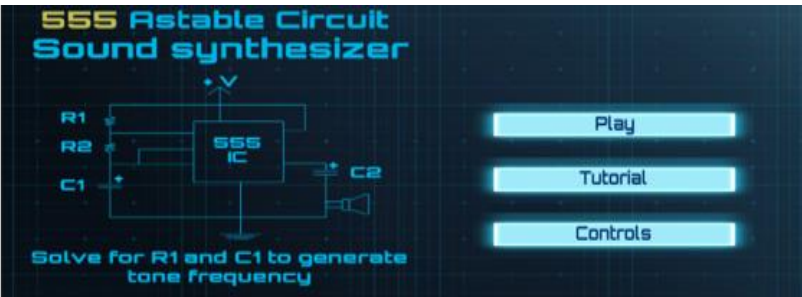

Figure 7 Game splash screen with high level overview

The game starts with the player in front of a notice board which plays the first part of a tune (in this instance the first 14 notes of Twinkle twinkle little star) and displays the musical notes and the target frequencies the player has to achieve to complete the game and starts the timer (Figure 8). The student has a maximum time of 3 minutes to calculate/select the correct permutations of $\mathrm{R} 1$ and $\mathrm{C} 1$ and connect the battery to generate the required individual output frequencies in sequence (Figures 9-12). Overall score is based on total time taken to complete the tune(s) across a number of segments/levels. The game will be extended to include more levels/tunes as development continues.

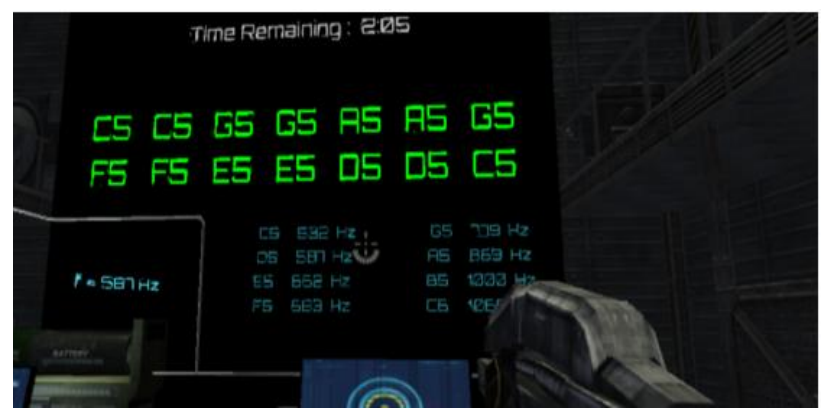

Figure 8 Target frequency/sequence to achieve

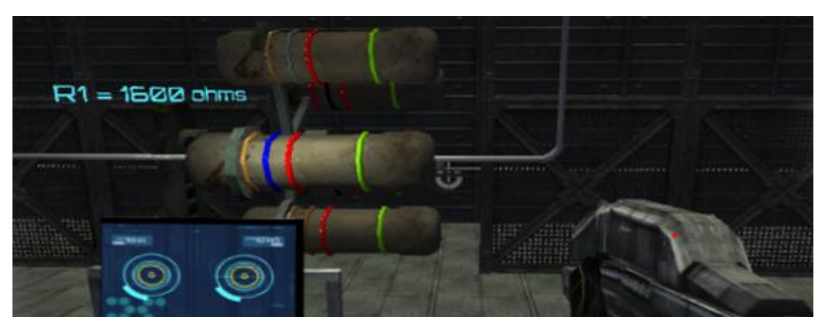

Figure 9 Select correct value of Resistor R1

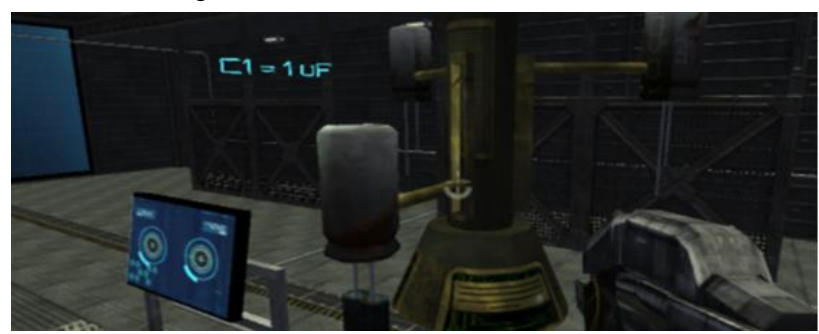

Figure 10 Select correct value of Capacitor C1

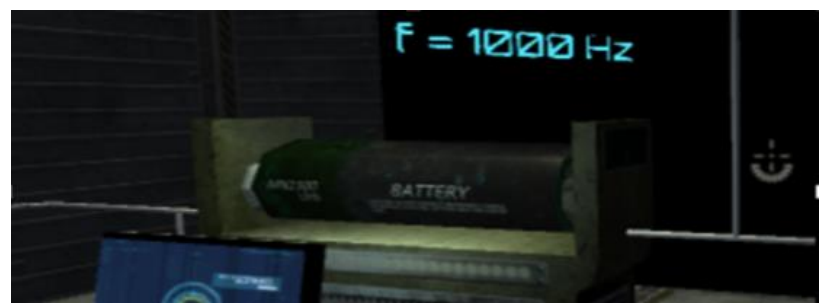

Figure 11 Connect battery to generate frequency

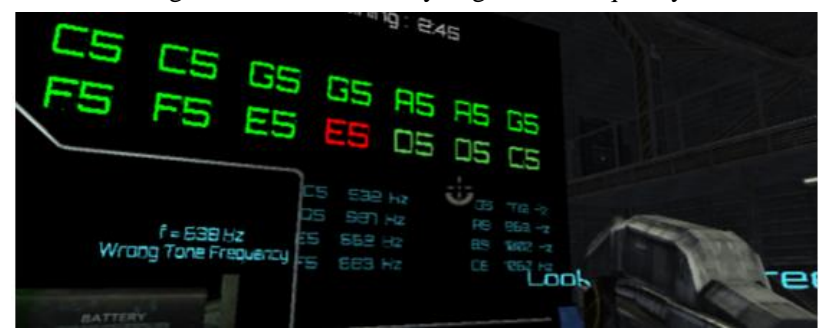

Figure 12 Move to next note in sequence

V. ASSESSMENT AND ANALYTICS

Assessment of learning in SG relates to the process of using data to demonstrate that the stated learning objectives are been met by a learner and involves interlacing game mechanics oriented to facilitate building new knowledge with mechanics oriented to assess the new knowledge acquired [12]. The Tone Generator game uses a summative and formative approach to assessment (Table 6). Formative assessment is stealth based/implicit and carried out throughout the game, continuously monitoring student progress and providing feedback through the ingame score. This approach has a number of advantages as it can be carried out in real time without interrupting the user's flow [13]. Elements of formative assessment include the time taken to complete level(s) and score achieved per level (Table 6). Summative assessment will be carried out at the end of the game with an overall total accumulated score. A global leader board adds a competitive element to the game allowing the student to benchmark their performance against others.

Recent advances in game and learning analytics have allowed developers and educators to gain new insights into how users interact with their games by simplifying the collection of large amounts of data. 
Table 6 Assessment dataset

\begin{tabular}{|l|l|}
\hline \multicolumn{1}{|c|}{ Data point } & \multicolumn{1}{c|}{ Description } \\
\hline $\begin{array}{l}\text { Global score } \\
\text { (completion) }\end{array}$ & $\begin{array}{l}\text { Total score when completing game. } \\
\text { Displayed after final level. }\end{array}$ \\
\hline $\begin{array}{l}\text { Global time } \\
\text { (completion) }\end{array}$ & $\begin{array}{l}\text { Total time taken to complete game. } \\
\text { Displayed after final level. }\end{array}$ \\
\hline Time per level & Time per level. Shown at level end. \\
\hline Score per level & Level scores. Shown at level end. \\
\hline Connect components & Indicator attempts on each level. \\
\hline
\end{tabular}

Serrano-Laguna et al., proposed a two-step generic approach to using learning analytics in educational games [14] where in-game measures/generic traces are gathered from gameplay and then queried using specific assessment rules aligned with the games educational objectives. Game analytics [15] offer similar functionality in the form of core and custom metrics. Core analytics measure standard metrics e.g. general game usage, daily and monthly active users, time of day and length of sessions. Custom metrics can record game specific actions or traces of interest decided on during the game design process e.g. level completion or score which can be cross referenced and analyzed further using cohorts and funnels [15]. The Tone Generator game uses a combination of core and custom analytics to track user activities. As the game design evolves in later iterations or is enhanced, the use of analytics would allow the educator to check the impact on usage and retention these changes caused e.g. changing the relative difficulty of a level and adding or removing features. Using a combination of assessment and analytics can provide educators with the tools to quantify the effectiveness of the learning activities and can serve as a starting point for validation to evaluate whether the game achieves its purpose and learning outcomes are met.

\section{CONCLUSION, FUTURE WORK AND DISCUSSION}

This paper provides a practical case study and summary of ongoing research and development at the School of Computing and Intelligent Systems, Ulster University, Northern Ireland into the use of serious games for teaching electrical and electronic circuit theory. The Tone Game project was introduced and the rationale, concept development, planning and ongoing implementation of the game using a Sand Box Serious Game/heuristic approach presented. The practical use of the Learning MechanicGame Mechanic analysis framework in the game design process to map the pedagogical elements/learning outcomes to game elements while maintaining the balance between entertainment and learning was demonstrated. The design and integration of game analytics to assess student retention and engagement levels was discussed and a stealth approach to assessment implemented. The game design and implementation phase of the game is ongoing and the next stage in the project is the expansion of the number of game/puzzle levels and ongoing user testing.

Generalizing the approach taken in this project to other domains or application areas would involve identifying elements that would be common in any undertaking of this type and creating a generic framework for implementation i.e. set the context and player objectives using cut scenes, introduce the player to the core mechanics and control systems using a tutorial, create the physical layout of the level(s) and design the problem(s) to solve in a flexible manner for high replay value (incentivized by achievements) allowing different strategies to emerge, include regular updates and feedback on player progression and add an element of competition to the outcomes or final assessment using leader boards. However the main challenge(s) to overcome initially would be finding an approach to repurposing existing teaching material as a game experience and defining the core loop of the game in a compelling way.

\section{REFERENCES}

1. Prensky, M. Information and Background on The Monkey Wrench Conspiracy, http://www.marcprensky.com/ Last accessed 08/2015

2. Kosmadoudi, Z., Lim, T., Ritchie, J., Louchart, S., Liu, Y., Sung, R.: Eng. design using game-enhanced CAD 45 (3) (2013) 777-795

3. Aziz, E.-S., Esche, S. K. \& Chassapis, C.: Review of the state of the art in virtual learning environments. Computers in Education Journal, Vol. 20, No. 1, pp. 22-35. (2010)

4. E. Klopfer, and S.Osterweil. "The Boom and Bust and Boom of Educational Games.” In Trans. Edutainment IX (2013): 290-296.

5. Quinn, C. N. (1994). Designing educational computer games. Designing for change in teaching and learning (A-59, pp. 45-57). Amsterdam: Elsevier Science.

6. Kiili, K. \& Lainema, T. (2008) Measuring Engagement in Educational Games. Inter. Learning Research. 19 (3). 469-488

7. Arnab, S., Lim, T., Carvalho, M.B., Bellotti, F., de Freitas, S. Louchart, S., Suttie, N., Berta, R. and De Gloria, A. (2014) Mapping learning and game mechanics for games analysis. British Journal of Educ. Technology Volume 46, Issue 2, pages 391-411, March 2015

8. M.J. Callaghan, K. McCusker, J.L. Losada, J.Harkin, S. Wilson. Using Game-Based Learning in Virtual Worlds to teach electronic and electrical engineering, IEEE Trans. on Industrial Informatics, vol. 9, no. 1, pp. 575-584, Feb 2013

9. MJ.Callaghan, K.McCusker, J.Losada, JG.Harkin and S.Wilson, Engineering Education Island: Innovation in Teaching and Learning in Sciences, Vol. 8 Issue 3 November (2009)

10. Dickey, M. D. (2005). Engaging by Design: How Engagement Strategies in Popular Computer and Video Games Can Inform Instructional Design. Educational Technology Research and Development, 53(2), 67-83.

11. F. Bellotti, M. Ott, S. Arnab, R. Berta, S. de Freitas, K. Kiili, and A. De Gloria, "Designing Serious Games for Education. ECGBL 2011: 5th European Conference on Games Based Learning

12. F.Bellotti, B.Kapralos, K.Lee, P.Moreno-Ger and R.Berta, R, "Assessment in and of Serious Games: An overview" In Advances in Human Computer Interaction, 2013, 11

13. Shute, V. J., Ventura, M., Bauer, M. I. \& Zapata- Rivera. D. (2009) Melding the power of serious games and embedded assessment. Serious Games: (pp 295-321) Routledge.

14. Serrano-Laguna, A. J.Torrente, P.Moreno-Ger B. FernándezManjón, "Application of Learning Analytics and Videogames for Student Assessment". Procedia Computer Science, 15, 203-209

15. Game Analytics, Last accessed 11/2015 from http://www.gameanalytics.com/

\section{AUTHORS}

Michael Callaghan is a Reader at Ulster University, Northern Ireland and leads the activities of the Serious Games and Virtual Worlds research team at the Intelligent Systems Research Center. Niall McShane, Augusto Gómez Eguíluz, Thomas Teillès (Polytech Montpellier) and Pierre Raspail (Polytech Montpellier) were placement students at the Intelligent Systems Research Center, Ulster University. 